\title{
Creep Deformation and Stress Relaxation of a Martensitic P92 Steel at $650^{\circ} \mathrm{C}$
}

\author{
Saber Khayatzadeh ${ }^{a, b^{*}}$, David W.J. Tanner ${ }^{c}$, Christopher E. Truman ${ }^{a}$, Peter E.J. Flewitt ${ }^{d}$, David J. Smith ${ }^{a} \dagger$ \\ ${ }^{a}$ Department of Mechanical Engineering, University of Bristol, Bristol, BS8 1TR, UK \\ ${ }^{\mathrm{b}}$ Advanced Forming Research Centre, Strathclyde University, Renfrew, Glasgow, PA4 9LJ, UK \\ ${ }^{c}$ ATKINS, The Hub, 500 Park Avenue, Aztec West, Bristol, BS32 4RZ, UK \\ ${ }^{\mathrm{d}}$ H H Wills Laboratory, School of Physics, University of Bristol, Bristol, BS8 1TL, UK \\ * Corresponding author. \\ E-mail address: saber.khayatzadeh@strath.ac.uk
}

\begin{abstract}
This paper develops methods to predict creep stress relaxation in the presence of combined boundary conditions and explores the influence of primary-secondary stress dependent creep properties on predictions for a martensitic P92 steel at temperature of $650^{\circ} \mathrm{C}$. A series of forward creep and elastic follow-up experiments have been conducted. A summary is provided of empirical creep equations for forward creep and creep stress relaxation (elastic follow-up) tests, including the link to the experimental procedure. The creep stress relaxation tests have been performed with two rigs to give elastic follow-up factors of 1.17 and 1.7. Both time hardening and strain hardening approaches have been considered where the strain hardening model provided more accurate predictions compared to time hardening; except at relatively low stress levels. The difference between stress relaxations predicted using strain hardening and time hardening approaches are considerable. The model predicts the creep stress relaxation accurately in the early stage of relaxation, indicating that the majority of stress relaxation occurs where primary creep needs to be taken into account. This study highlights the importance of stress dependent creep model to predict stress relaxation, especially with high level of initial residual stresses.
\end{abstract}

Keywords: Primary and Secondary Creep, Stress Relaxation, Elastic Follow-Up, P92 Steel, Creep Modelling

\section{Introduction}

There is a growing demand to increase the efficiency of electrical power generating plants, combined with a reduction of the $\mathrm{CO}_{2}$ emissions. This has led to an increase in the operating temperature and pressure in the steam raising boilers. As a consequence, there has been an increasing use of $9 \% \mathrm{Cr} 0.5 \% \mathrm{Mo}$ martensitic steels such as P91 and P92 which have an improved creep resistance. In this context P92 steel is one of the most commonly considered high $\mathrm{Cr}$ creep resistant steels [1-4]. This requirement to use improved creep resistance steels applies equally for future fossil fuel and nuclear power plants. To achieve the long life required for economic and safe operation, it is crucial to have a comprehensive understanding of material behaviour that provides an improved basis for plant life assessment [5-7].

There are two major factors, creep deformation and creep fracture, that affect the life expectancy of components operating at elevated temperature including minimizing the extent of creep strain accumulation [5, 8]. In practice to study material behaviour at high temperature, it is common to subject test specimens to often constant loads

\footnotetext{
$\dagger$ In memory of Professor David Smith, who died as the result of a tragic climbing accident during the period this paper was in preparation.
} 
at different temperatures to provide overall creep behaviour or constant displacement conditions to obtain stress relaxation behaviour under laboratory conditions.

\begin{tabular}{|ll|}
\hline Nomenclature & \\
$A$ & Cross Section Area $\left(\mathrm{mm}^{2}\right)$ \\
$E$ & Young's Modulus $(\mathrm{GPa})$ \\
$K$ & Stiffness $(\mathrm{KN} / \mathrm{mm})$ \\
$L$ & Length $(\mathrm{mm})$ \\
$Z$ & Elastic Follow-Up Factor \\
$\alpha$ & Relative Stiffness \\
$\mathrm{A}_{p}$ & Material Constant for Primary Creep \\
$\mathrm{A}_{s}$ & Material Constant for Secondary Creep \\
$\varepsilon_{\mathrm{T}}$ & Total Strain \\
$\varepsilon_{\mathrm{E}}$ & Elastic Strain \\
$\varepsilon_{\mathrm{P}}$ & Plastic Strain \\
$\varepsilon_{\mathrm{C}}$ & Creep Strain \\
$\varepsilon_{c}^{\text {Total }}$ & Total Creep Strain \\
$\varepsilon_{c}^{\text {Primary }}$ & Primary Creep Strain \\
$\varepsilon_{c}^{\text {Secondary }}$ & Secondary Creep Strain \\
$\varepsilon_{c}^{\text {Tertiary }}$ & Tertiary Creep Strain \\
$\dot{\varepsilon}_{\mathrm{c}}$ & Creep Strain Rate \\
$\dot{\varepsilon}_{e}$ & Elastic Strain Rate \\
$\dot{\varepsilon}_{\text {min }}$ & Minimum Creep Strain Rate \\
$\mathrm{m}_{p}$ & Time Exponent for Primary Creep \\
$\mathrm{m}_{s}$ & Time Exponent for Secondary Creep \\
$n_{p}$ & Stress Exponent for Primary Creep \\
$n_{s}$ & Stress Exponent for Secondary Creep \\
$t$ & Time (s) \\
$\sigma$ & Stress (MPa) \\
\hline
\end{tabular}

However, various engineering components usually operate between these two conditions leading to elastic follow-up $[6,7,9]$. Elastic follow-up occurs in structures and components when localized regions undergo nonlinear deformation while the surrounding global material remains elastic. Therefore engineering components subjected to creep strain accumulation at elevated temperature in the presence of elastic follow-up, leads to stress relaxation [10]. It is therefore important to have models that predict creep deformation accumulation under conditions where elastic follow-up in present. This has recently led to developing stress dependent creep behaviour of materials [11-14], compared to considering only a single creep regime over a wide range of stresses [4, 15-23]. This application has provided models with increased accuracy of the life prediction, especially in the presence of geometric discontinuities such as cracks or relaxation of stresses [5].

A variety of different equations, such as RCC-MR [24-26], have been used to describe creep deformation for various high temperature steels, e.g. Type 316 [24, 27-29], when subjected to different temperatures [5, 30]. As a general conclusion, these revisions were important so that a reduction in the stress level either increased or decreased the accuracy, especially in early stages of creep relaxation. In the latest research conducted by Wang et al [24] on Type $316 \mathrm{H}$ austenitic stainless steel, it was proposed that a RCC-MR model considering creep properties based on the average creep strain rate did not predict accurately the stress relaxation. In general it under-estimated the initial stages and over-estimated the later stages of relaxation. It was argued by Wang et al [24] that the initial stages of stress relaxation are dominated by primary creep for a fixed displacement. However, 
these remains a need to evaluate the contribution of primary creep to creep strain accumulation in the presence of relaxation of stresses.

This study determines the creep stress relaxation for a $9 \% \mathrm{Cr} 0.5 \%$ Mo martensitic $\mathrm{P} 92$ steel at a temperature of $650^{\circ} \mathrm{C}$ in the presence of elastic follow-up by taking into account both primary and secondary stress dependent creep properties. Experimental procedures for both forward and elastic follow-up creep tests are described in Section 2, and followed by results in Section 3. In Section 4, a summary of the constitutive equations for creep deformation and stress relaxation, followed by developing a stress dependent creep model that is appeared to uniaxial creep elastic follow-up. In Section 5 the results are discussed and comparisons are made between experimental data and model predictions.

\section{MATERIAL AND EXPERIMENTS}

\subsection{Material}

The material for this research was ASME grade P92 steel extracted from a pipe, with inner and outer diameter of $290 \mathrm{~mm}$ and $350 \mathrm{~mm}$, respectively [5]. Table 1 shows the chemical composition of P92 steel [31]. After fabrication, the pipe was normalised at a temperature of $1070^{\circ} \mathrm{C}$ for 45 minutes and then air cooled and further heat treated at $780^{\circ} \mathrm{C}$ for 105 minutes, followed by heat treatment at a temperature of $760^{\circ} \mathrm{C}$ for 180 minutes [5]. The latter was conducted to relieve residual stress associated with weldments elsewhere in the pipe; the material used was removed from a position remote from a weldment.

Table 1: Chemical composition of P92 (wt \%) [31]

\begin{tabular}{ccccccccccccccc}
\hline $\mathrm{Ni}$ & $\mathrm{C}$ & $\mathrm{Mn}$ & $\mathrm{P}$ & $\mathrm{S}$ & $\mathrm{Si}$ & $\mathrm{Cr}$ & $\mathrm{W}$ & $\mathrm{Mo}$ & $\mathrm{V}$ & $\mathrm{Nb}$ & $\mathrm{N}$ & $\mathrm{B}$ & $\mathrm{Al}$ & $\mathrm{Fe}$ \\
\hline 0.27 & 0.10 & 0.45 & 0.015 & 0.002 & 0.45 & 8.62 & 1.86 & 0.33 & 0.21 & 0.076 & 0.047 & 0.003 & 0.019 & Bal. \\
\hline
\end{tabular}

\subsection{Uniaxial Constant Load Creep Tests}

Round bar test specimens $(5.65 \mathrm{~mm}$ diameter and $28.25 \mathrm{~mm}$ gauge length) extracted from the pipe. The specimens cut from the end of the pipe remote from weldment had a uniform microstructure along each specimen and parallel to the axis of the pipe [5]. The microstructure was a tempered martensite with a prioraustenite grain size of $35 \mu \mathrm{m}$ (mean grain value). The geometry of the uniaxial specimens for forward creep tests was designed to the ASTM standard E8 [32]. Elongation of the gauge length was measured using an extensometer connected from the bottom (outside of the furnace and at room temperature) to linear voltage displacement transducers (LVDT). In total, four thermocouples were used to measure the temperature during the creep tests; three thermocouples were connected to the specimen (top, middle and bottom of the gauge) to monitor the test temperature and another monitored the room temperature. The lever arms on the creep test rigs (using deadweight) were controlled automatically to remain horizontal during a test. The load cell, connected to the data logger, was embedded at the base of the rig and measured the applied load on the specimen during the test.

\subsection{Elastic Follow-Up Tests}

Uniaxial creep stress relaxation tests under elastic follow-up conditions were conducted using two different test rigs with elastic follow-up factors $(\mathrm{Z})$ of 1.17 and 1.7. In each case, the extension of the gauge length of the specimen was measured following the same procedure described for the forward creep tests. The geometry of the specimen was different for each rig depending on the specific elastic follow-up factor, as shown in Fig. 1a and $b$.

A novel creep stress relaxation test rig, shown in Fig. 2a, was designed [5] to provide a low elastic follow-up factor of 1.17. The concept of this test rig is based on the three bar structure [5,33] (Fig. 2b), with the difference that the central bar is only enclosed in a furnace and parallel bars are outside. A similar creep test rig was 
proposed by Wang [30] for conducting stress relaxation $(\mathrm{Z}=1.25)$ using type $316 \mathrm{H}$ stainless steel at $550^{\circ} \mathrm{C}$. The proposed test rig in this research, was manufactured to provide $Z=1.17$ at a higher temperature of $650^{\circ} \mathrm{C}$, by increasing the stiffness of the series bars to the test specimen (Fig. 2a). Originally the test rig of $Z=1.7$ was developed to investigate creep crack incubation in stainless steel type $316 \mathrm{H}$, using compact tension geometry specimens, at $550^{\circ} \mathrm{C}$ with $\mathrm{Z}=2$, however for uniaxial specimens of $\mathrm{P} 92$ steel, $\mathrm{Z}$ reached 1.7. Due to the robust side bars in the test rig of $Z=1.17$ (Fig. 2a), it was feasible to introduce the initial residual stress by misfit [5, 30]. In the case of the test rig for $Z=1.7$ (Fig. 2b), the initial residual stress level could be introduced by both external load and misfit $[5,33]$. Further details of the rigs can be found in references $[5,30]$.
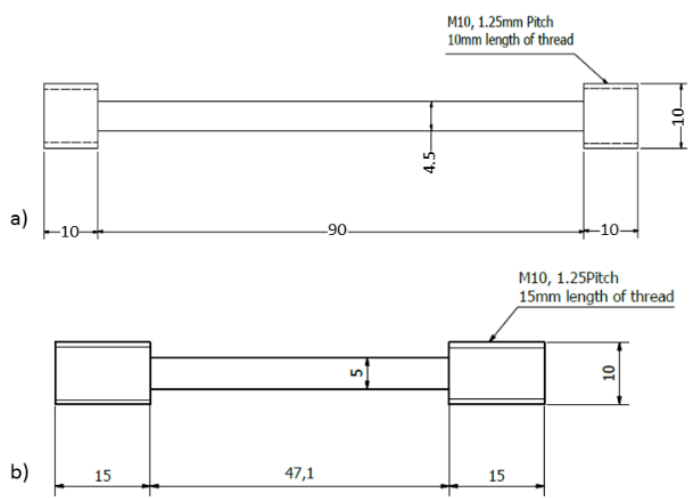

Fig. 1: Schematic of uniaxial specimens for elastic follow-up creep stress relaxation test. a) $Z=1.17$. b) $Z=1.7$ (all dimensions in $\mathrm{mm}$ )

a)

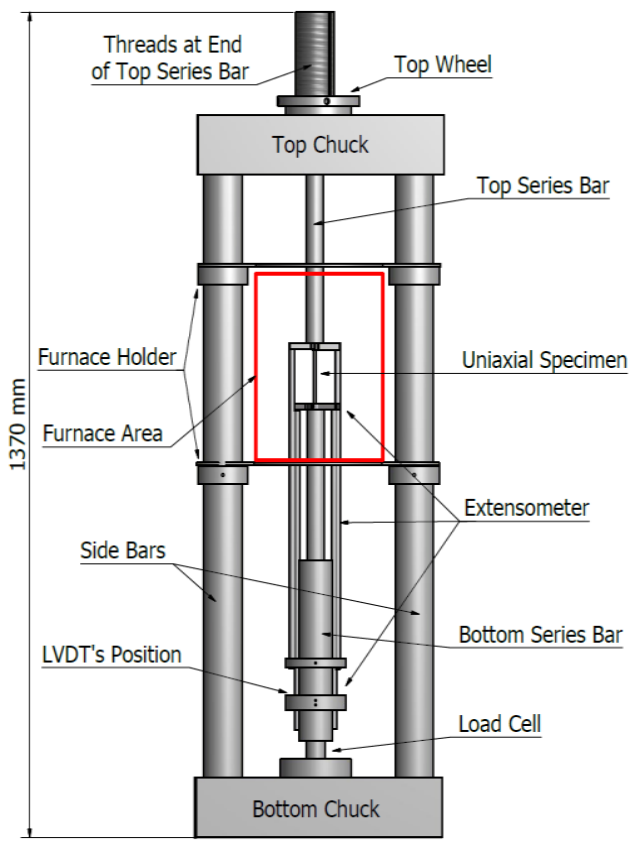

b)

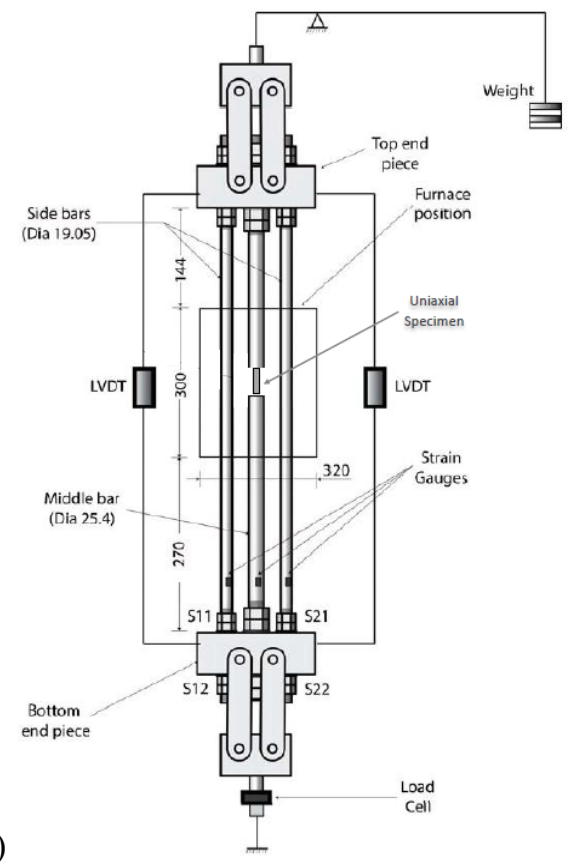

Fig. 2: Uniaxial creep stress relaxation test rig used to evaluate elastic follow-up: a) $Z=1.17$, b) $Z=1.7$. (all dimensions in $\mathrm{mm})$

\section{Results}

\subsection{Forward Creep Tests}

The uniaxial creep tests were conducted within an applied stress range of $40 \mathrm{MPa}$ to $170 \mathrm{MPa}$ at $650^{\circ} \mathrm{C}$. Two specimens were tested to rupture at stress levels of $120 \mathrm{MPa}$ and $170 \mathrm{MPa}$, and the remainder of tests were interrupted within the secondary creep regime to allow the minimum creep strain rate to be determined with confidence [5]. All the tests were conducted under elastic creep conditions, normally below the yielding point measured to be $273 \mathrm{MPa}$ at $650^{\circ} \mathrm{C}$ [5]. Table 2 summarizes the details of the creep tests at constant load for the 
P92 steel at $650^{\circ} \mathrm{C}$, including the minimum creep strain rate for each applied stress. Typical creep curves from constant load tests at the various stress levels are shown in Fig. 3a. Increasing the stress, from 40MPa to $170 \mathrm{MPa}$ (tests T6 to T4), the minimum creep strain rate changed from $2 \times 10^{-7}$ to $8 \times 10^{-3}$. This change is more obvious in the range between $120 \mathrm{MPa}$ and $170 \mathrm{MPa}$ where the rupture life reduced by over 100 times and the failure strain doubled.

The creep strain rate at constant load condition decreases by from the start of test and reaches the minimum value before commencing tertiary creep. This is evident for tests T1 (170MPa) and T2 (120MPa) in Fig. 3b, where they ruptured after 7.2 and 760 hours creep, respectively. For other tests at constant load with lower stress levels, the minimum creep strain rate resulted in a longer time before the test was terminated.

Table 2: Details of uniaxial creep tests at constant load

\begin{tabular}{|c|c|c|c|c|c|c|}
\hline Test ID & $\mathrm{T} 1$ & $\mathrm{~T} 2$ & T3 & $\mathrm{T} 4$ & T5 & T6 \\
\hline $\begin{array}{c}\text { Nominal Applied Stress } \\
\text { (MPa) }\end{array}$ & 170 & 120 & 100 & 80 & 60 & 40 \\
\hline $\begin{array}{c}\text { Measured Minimum Creep } \\
\text { Strain Rate, } \dot{\varepsilon}_{\min }(1 / \mathrm{hr})\end{array}$ & $8.00 \times 10^{-3}$ & $3.73 \times 10^{-5}$ & $1.27 \times 10^{-5}$ & $3.48 \times 10^{-6}$ & $1.20 \times 10^{-6}$ & $3.41 \times 10^{-7}$ \\
\hline Failure Strain $\left(\varepsilon_{f}\right), \%$ & 34.5 & 16.7 & ---- & ---- & ---- & ---- \\
\hline Failure Time (hr) & 7.2 & 807 & ---- & ---- & ---- & ---- \\
\hline
\end{tabular}

\subsection{Elastic Follow-Up Tests}

Table 3 provides the details of the uniaxial stress relaxation tests. Only one test was performed with the initial residual stress generated by external load, and the rest of the tests addressed misfit. Experimental results for the uniaxial creep stress relaxation tests for the P92 steel at $650^{\circ} \mathrm{C}$ subjected to different levels of misfit (initial residual stress) and elastic follow-up are shown in Fig. 4. This figure also contains the curve for test T2 undertaken with constant stress of $120 \mathrm{MPa}$. These data remained constant over the time, and provide a comparison between the relaxation of stresses under different boundary conditions. The highest relaxation occurred in test EFU-2 ( $Z=1.17)$ with initial residual stress of 123MPa. Test EFU-1 ( $Z=1.7)$, despite having a higher residual stress, had a slightly lower relaxation rate compared to test EFU-2, which later had a lower elastic follow-up factor. A similar case occurred for tests EFU-3 and EFU-4. The lower the elastic follow-up factor and the higher the initial residual stress, the more stress is relaxed.

The experimental creep strain accumulation in the uniaxial specimen for tests EFU-3 and EFU-4, compared to tests T4, T5, and T6, are shown in Fig. 5a. The creep strain accumulation was similar for both tests EFU-3 and EFU-4, as they had follow-up values of 1.17 and 1.7, compared to tests T4, T5, and T6, conducted at constant load $(Z=\infty)$. There was significantly more creep strain accumulation for the constant load tests compared to elastic follow-up conditions, since there was no reduction in the load. Both EFU-3 and EFU-4 tests experienced a large amount of creep strain accumulation (similar to constant load tests) among the early stages, and after the first 100 hours there was little change in the level of creep strain accumulation. This coincided with a significant reduction in the initial level of residual stress during this period, which reduced from $83 \mathrm{MPa}$ to almost $20 \mathrm{MPa}$ for test EFU-4, and from 99MPa to around 47MPa for test EFU-3. These results indicated that the magnitude of creep strain accumulation arises from an increase in the elastic follow-up factor for the structure, up to a level where the highest value is reached for the constant load condition. The creep strain rate for uniaxial creep stress relaxation tests of EFU-3 and EFU-4 were compared to the rate of those conducted at constant load (Fig. 3b). For elastic follow-up tests (EFU-3 and EFU-4), despite having higher initial residual stress levels compared to tests (T4, T5 and T6), the rate decreased continuously. For such tests with low elastic follow-up, the stress relaxes quickly and the tertiary creep stage was not reached.

Table 3: Details of stress relaxation tests with elastic follow-up 


\begin{tabular}{cccccccc}
\hline Test ID & $\begin{array}{c}\text { EFU Factor, Z } \\
\text { (Theoretical) }\end{array}$ & $\begin{array}{c}\text { EFU Factor, Z } \\
\text { (Experimental) }\end{array}$ & $\begin{array}{c}\text { Type of Residual } \\
\text { Stress }\end{array}$ & $\begin{array}{c}\text { Test Duration } \\
(\mathrm{hr})\end{array}$ & $\begin{array}{c}\sigma_{\text {initial }} \\
(\mathrm{MPa})\end{array}$ & $\begin{array}{c}\sigma_{\text {final }} \\
(\mathrm{MPa})\end{array}$ & $\begin{array}{c}\Delta \sigma \\
(\mathrm{MPa})\end{array}$ \\
\hline EFU-1 & 1.7 & 1.83 & External Load & 558 & 133 & 50 & 83 \\
EFU-2 & 1.17 & --- & Misfit & 584 & 123 & 37 & 86 \\
EFU-3 & 1.7 & 1.73 & Misfit & 498 & 99 & 40 & 59 \\
EFU-4 & 1.17 & 1.14 & Misfit & 768 & 83 & 8 & 75 \\
\hline
\end{tabular}

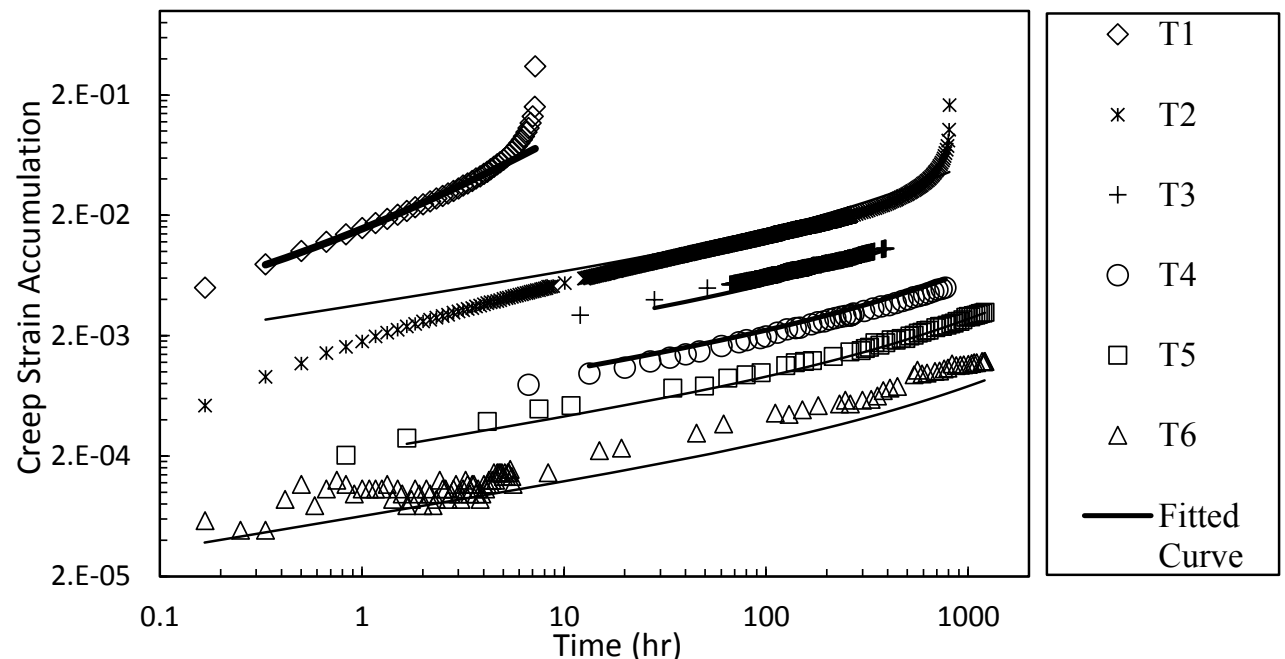

a)

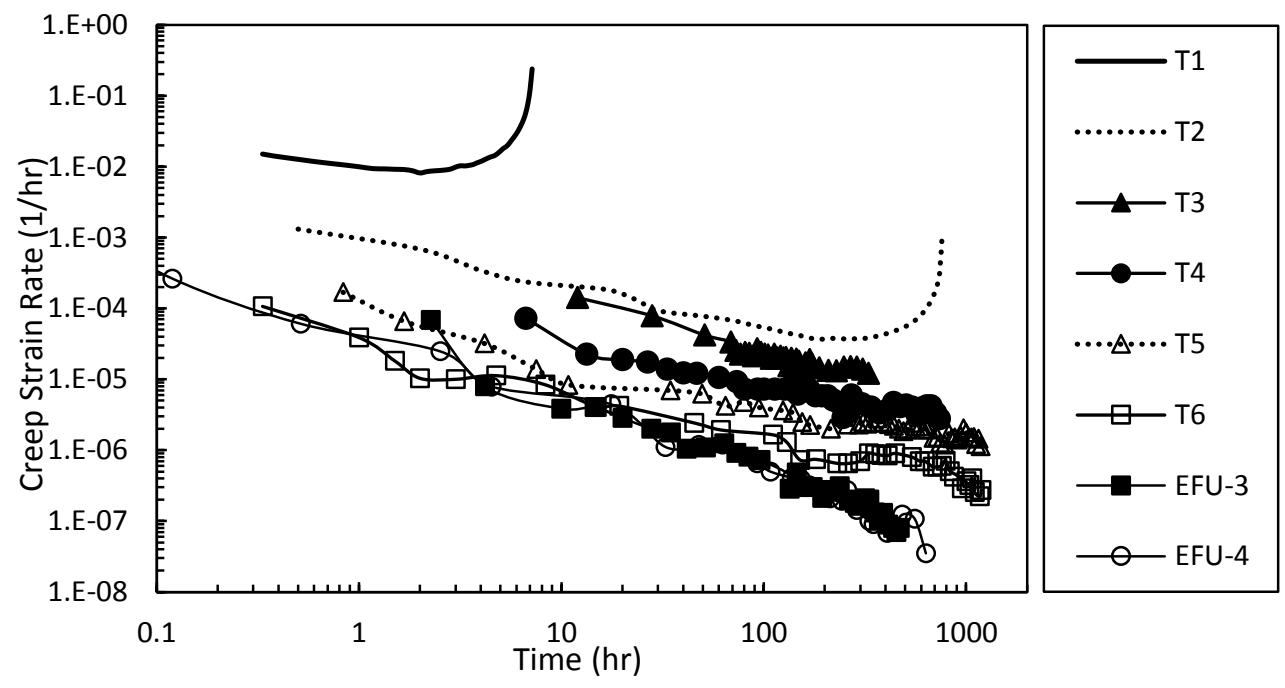

Fig. 3: a) Experimental creep curves for $P 92$ steel at $650^{\circ} \mathrm{C}$, compared with the fitted curves for tests $\mathrm{T} 1$ to $\mathrm{T} 6$. b) Experimental creep strain rate for uniaxial creep stress relaxation tests at constant load and elastic follow-up for P92 steel at $650^{\circ} \mathrm{C}$

Fig. 5b shows experimental stress-strain curves for all the uniaxial creep elastic follow-up tests conducted for P92 steel at $650^{\circ} \mathrm{C}$. The curve for test EFU-2 has been excluded due to the uncertainty in the measured strain values. The measured experimental elastic follow-up factor $\left(Z_{e}\right)$ is stated for each test. This figure also includes the stress-strain curve for test $\mathrm{T} 2$, conducted at the $120 \mathrm{MPa}$ constant load condition, to highlight the difference between constant load and elastic follow-up. As shown the slope of the creep curve in the early stages were linear and identical; the elastic range to achieve the target initial stresses for each elastic follow-up factor. On increasing the elastic follow-up factor from unity towards infinity, the slope increased. Tests EFU-1 and EFU3 had similar experimental EFU factors to the theoretical (designed, 1.7) value of the rig; test EFU-4 had a lower value of $Z$ (1.17), hence the lower slope of the curve compared to the others. 


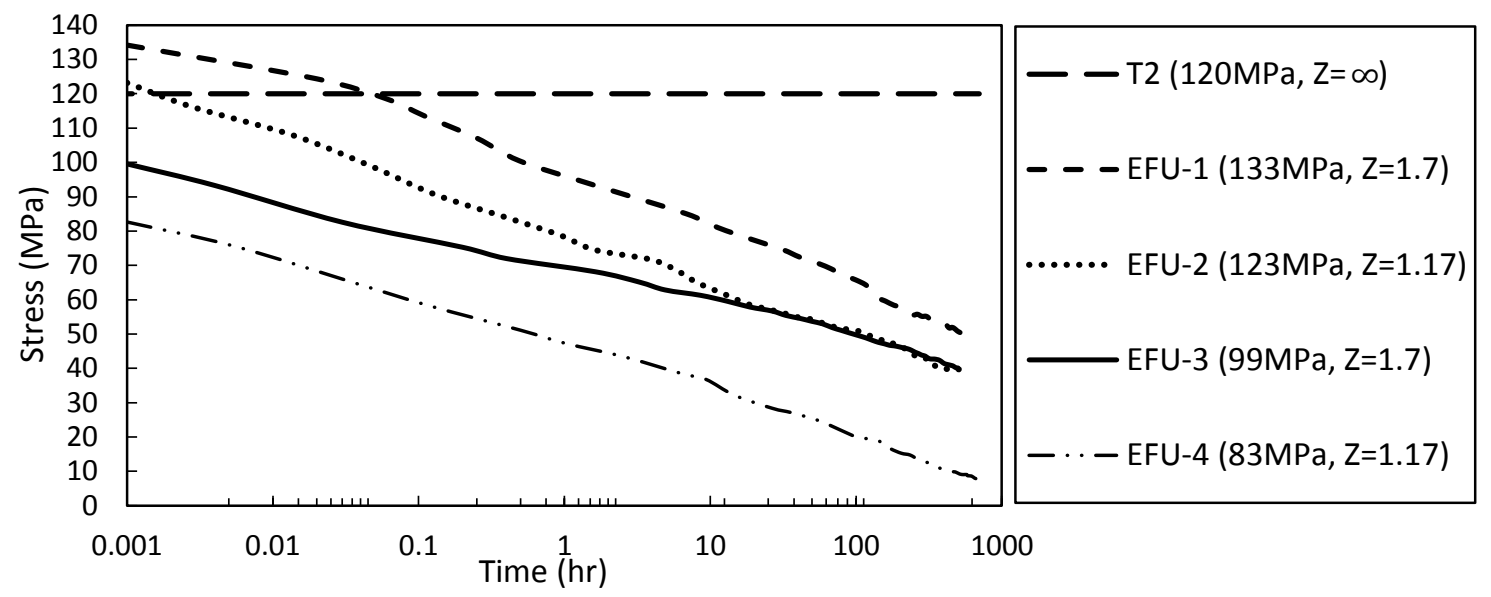

Fig. 4: Experimental uniaxial creep stress relaxation of P92 steel with a variety of levels of initial residual stress and elastic follow-up

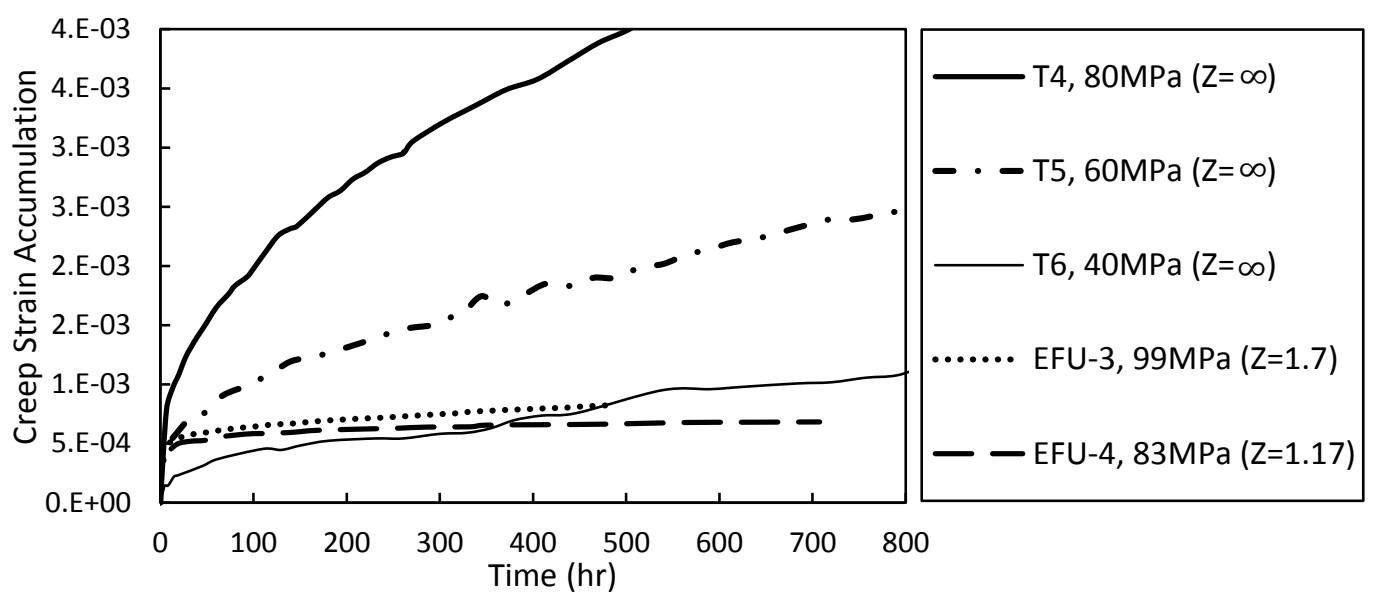

a)

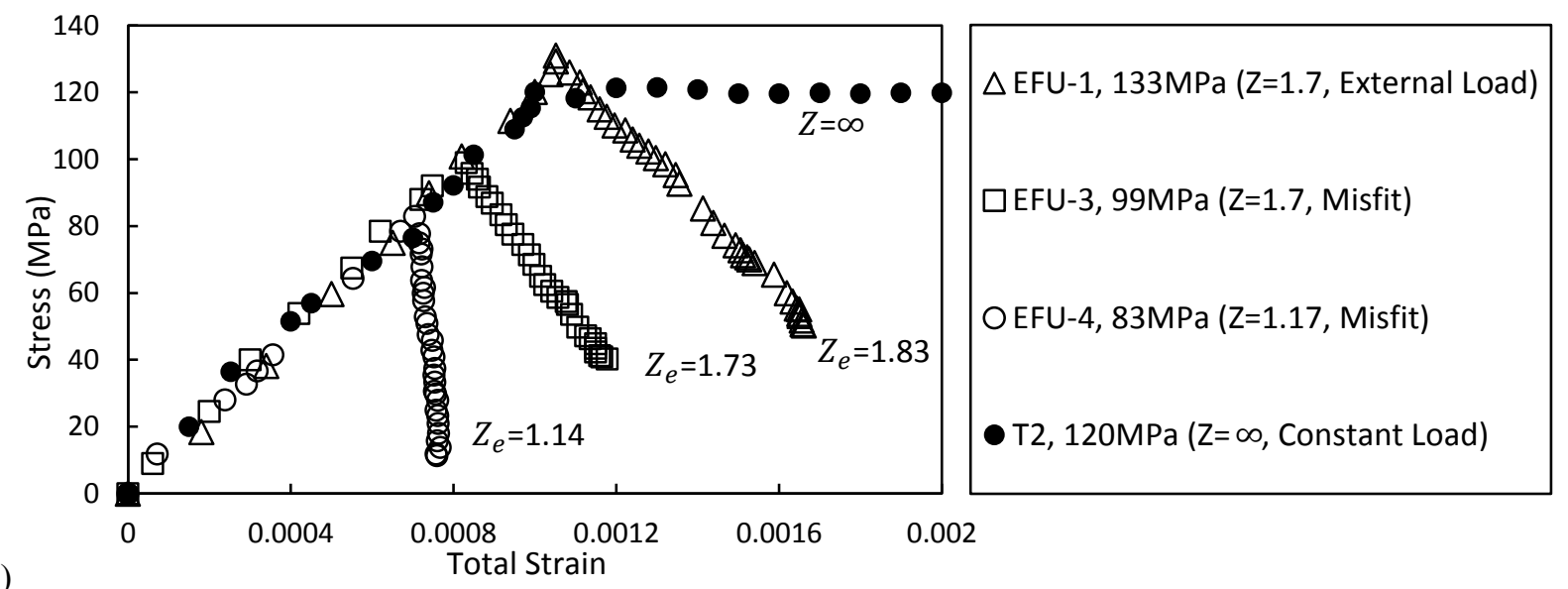

Fig. 5: a) Experimental creep strain accumulation in uniaxial specimens at constant load and elastic follow-up. b) Experimental stress-strain curve for uniaxial creep stress relaxation results compared to test $\mathrm{T} 2$ at constant load of $120 \mathrm{MPa}$ (measured experimental elastic follow-up factor $\left(Z_{e}\right)$ ).

\section{Modelling}




\subsection{Creep Deformation and Relaxation}

A typical creep strain curve, obtained from a standard creep uniaxial specimen at a fixed load condition, consists of three distinct stages, namely: primary, secondary, and tertiary creep. The total creep strain $\left(\varepsilon_{c}^{\text {Total }}\right)$ accumulated in a material is [5]:

$\varepsilon_{c}^{\text {Total }}=\varepsilon_{c}^{\text {Primary }}+\varepsilon_{c}^{\text {Secondary }}+\varepsilon_{c}^{\text {Tertiary }}$

where $\varepsilon_{c}^{\text {Primary }}, \varepsilon_{c}^{\text {Secondary }}$, and $\varepsilon_{c}^{\text {Tertiary }}$ are the primary creep, secondary creep, and tertiary creep strains. In the present research, the focus has been on the primary creep and secondary creep stages.

Primary creep can occupy a significant fraction of creep life for most engineering metallic alloys [5]. Therefore, it is important to accommodate primary creep in predictive models, especially during creep stress relaxation. There are a variety of equations for describing primary creep strain $\left(\varepsilon_{c}^{\text {Primary }}\right)[8,11,34,14]$, but a commonly adopted is via a power law function [6]:

$\varepsilon_{c}^{\text {Primary }}=\mathrm{A}_{p} \sigma^{\mathrm{n}_{p}} \mathrm{t}^{\mathrm{m}_{p}}$

where $\mathrm{A}_{p}, \mathrm{n}_{p}$, and $\mathrm{m}_{p}\left(0<\mathrm{m}_{p}<1\right)$ are material constants. The general form of power law equation for secondary creep is $\left(\varepsilon_{c}^{\text {Secondary }}\right)$ given by [5]:

$\varepsilon_{c}^{\text {Secondary }}=\mathrm{A}_{s} \sigma^{\mathrm{n}_{s}} \mathrm{t}^{\mathrm{m}_{s}}$

where $\mathrm{A}_{s}, \mathrm{n}_{s}$, and $\mathrm{m}_{s}$ are material constants for power law creep during secondary creep. Combining Eqs. 2 and 3 gives a general form to describe creep strain for a material taking into account both primary and secondary creep:

$\varepsilon_{\mathrm{c}}=\mathrm{A}_{p} \sigma^{\mathrm{n}_{p}} \mathrm{t}^{\mathrm{m}_{p}}+\mathrm{A}_{s} \sigma^{\mathrm{n}_{s \mathrm{t}}}$

During the secondary creep the slope of creep strain can be assumed to remain constant, the time exponent equals unity $\left(\mathrm{m}_{s}=1\right)[5]$. There is a variety of approaches adopted when combining primary with secondary creep. The most common method, also used by Wang et al [24] in RCC-MR for stainless steel type 316H, considers a transition time, $t_{p}$, where primary creep ends and secondary creep begins, as shown in Fig. 6a. This is an impediment when seeking to clarify the transition time from primary to secondary creep and a latent source of imprecision. However, in the present study, the transition time from primary to secondary creep, $t_{p}$, is eliminated by using Eq. 4, and assuming that the secondary creep commences at the beginning of creep, shown in Fig. 6b, and the sum of primary creep strain and secondary creep strain provide the total accumulated creep strain.

The rate of creep strain $\left(\dot{\varepsilon}_{\mathrm{c}}\right)$ is a key factor when considering the accumulation of creep deformation in a component. This can be expressed as either time hardening or strain hardening [30]. For time hardening, the creep strain rate is described as a function of stress, temperature, and time, and based on Eq. 4, given by:

$\dot{\varepsilon}_{c}=A_{p} \sigma^{\mathbf{n}_{p}} \mathbf{m}_{p} \mathbf{t}^{\mathbf{m}_{p}-1}+\mathbf{A}_{s} \sigma^{\mathbf{n}_{s}}$

Thus, strain hardening (Eq. 4), defines the creep strain rate as a function of stress, temperature, and creep strain accumulation: 
$\dot{\varepsilon}_{\mathbf{c}}=\mathbf{A}_{p}{ }^{1 / \mathbf{m}_{p}} \boldsymbol{\sigma}^{\mathbf{n}_{p} / \mathbf{m}_{p}}\left(\mathbf{m}_{p} \varepsilon_{\mathbf{c}}\right)^{\left(\mathbf{m}_{p}-1\right) / \mathbf{m}_{p}}+\mathbf{A}_{s} \boldsymbol{\sigma}^{\mathbf{n}_{s}}$

Equations (Eqs. 5 and 6) are only relevant during primary creep. The minimum creep strain rate, $\dot{\varepsilon}_{\text {min }}$ (at constant load and temperature), can be defined in the secondary creep regime by [30]:

$\dot{\varepsilon}_{\min }=\mathrm{A}_{s} \sigma^{\mathrm{n}_{s}}$

Creep strain is a time dependent permanent strain, as described in Eq. 2. Therefore, considering the changes of strain with time for pure displacement control (constant total strain) gives:

$\dot{\varepsilon}_{c}(\mathrm{t})=-\dot{\varepsilon}_{e}(\mathrm{t})=-\frac{1}{E} \frac{d \sigma}{d t}$

where $\dot{\varepsilon}_{c}$ and $\dot{\varepsilon}_{e}$ are the creep rate and elastic strain rate respectively. Creep stress relaxation is the conversion of elastic strain to creep strain under constant total strain. The uniaxial creep stress relaxation can be computed at a given time based on a specific creep law. Normally, only primary and secondary creep strains are considered during the relaxation since it is unlikely the tertiary stage of creep reached [30]. Since the creep strain rate can be described using either a time or strain hardening approach (Eq. 6 and 7), then creep stress relaxation can be expressed similarly.

a)

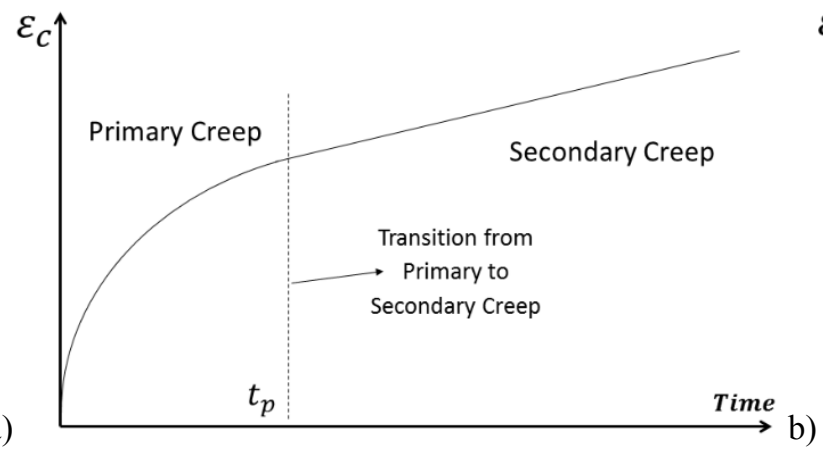

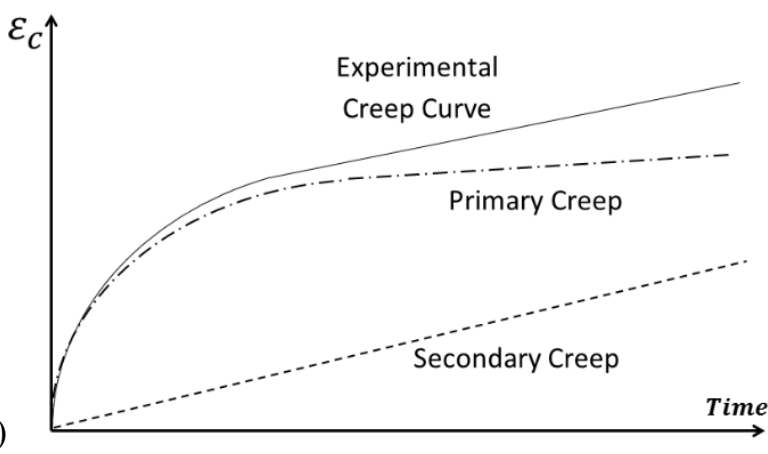

$\underset{\mathrm{Time}}{\longrightarrow}$

Fig. 6: Schematic illustration of creep curve: a) considering a transition time from primary to secondary creep, b) considering a combination of primary and secondary from beginning of creep.

\subsection{Stress Dependent Creep Model}

Since engineering components in service are subjected to a wide range of stress levels and temperatures, models are required to represent the creep behaviour for such a range of conditions [14]. For many engineering alloys, creep deformation mechanisms at low stress levels are different from those at high stresses $[21,14]$ and $9 \% \mathrm{Cr}$ steels, such as P92, are classified among the steels that exhibit differences [21]. Conventional creep models that consider only one creep regimes across a range of stresses have been employed by many researchers $[3,4,13$, $15,16,18-20,22,23,35]$. A few studies have considered two creep regime models with appropriate creep properties (secondary creep) over a wide range of stresses [13, 21-23, 35]. Also, limited studies have employed a similar approach to study creep crack growth [36-40]; however discussing their findings when applied to the behaviour of cracks is beyond the scope of this paper. A few previous studies [11, 14] have considered primary, secondary and tertiary stages for two creep regimes. Hosseini et al [14] argued that having a two creep regime model was more successful in predicting the creep deformation of cracked components compared to single regime model. Another example of the beneficial application of stress dependent creep properties would be for creep stress relaxation, where the creep regime changes as the stress relaxes. This concept was explored in a study conducted by Wang et al [24] where creep stress relaxation for Type $316 \mathrm{H}$ was determined by considering stress dependent creep properties and a linear relationship between creep properties and stress was observed. However, a non-linear relationship was discovered in the present study for P92 steel. 
Fig. 7 shows experimental results of minimum creep rate for a range of stresses applied to the $\mathrm{P} 92$ steel at $650^{\circ} \mathrm{C}$, based on Eq. 8 and the forward creep tests undertaken in this work (also summarized in Table 2). The results are also compared with the available creep data for P92 steel conducted at the same temperature $[4,13,22,23$, $35,41]$. Following a detailed analysis of these data presented in

Fig. 7, we have adopted an approach used by other researchers [13, 21-23, 35] to identify the distinct creep regimes of I, II and III. Each of these regimes was fitted linearly with a high measure of statistical confidence given by the R-squared value (

Fig. 7). The minimum creep strain rate is plotted as a function of the applied stress and three stress dependent creep regimes divide into the ranges $40 \mathrm{MPa}$ to $85 \mathrm{MPa}, 85 \mathrm{MPa}$ to $140 \mathrm{MPa}$, and stress levels above $140 \mathrm{MPa}$. The experimental creep rate exponents $\left(n_{s}\right)$ for regimes I, II and III are 3.3, 5.8 and 22, respectively. Table 4 summarizes the material constants for $\mathrm{P} 92$ steel at $650^{\circ} \mathrm{C}$ derived from experimental data and based on Eq. 4 for primary and secondary creep as a function of stress, excluding tertiary creep. This creep deformation model consists of three distinct regions. Based on the creep regimes and computed creep properties for primary and secondary (Table 4), the creep strain curves were calculated using Eq. 4, as shown in Fig. 3. The agreement is good, when tertiary creep has been omitted from the analysis. As shown in Fig. 3, there is a difference between the prediction and experiment results in early stages of test $\mathrm{T} 2$ which perhaps could be due to inaccuracy in the stress level around the transition from regime II to III.

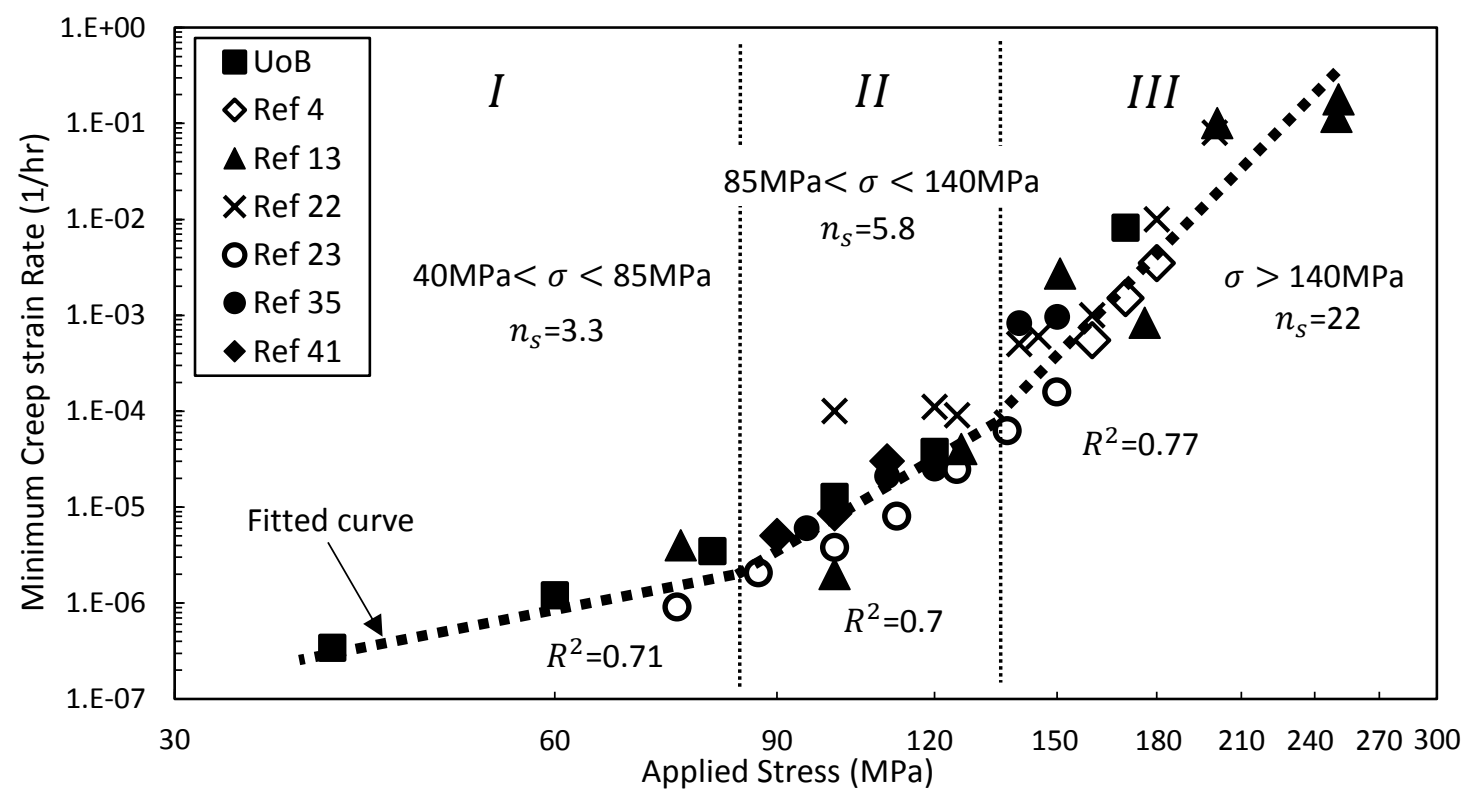

Fig. 7: Minimum creep strain rate against the applied stress level for $\mathrm{P} 92$ steel at $650^{\circ} \mathrm{C}$. (UoB presents experimental data gathered in the present research)

Table 4: Creep properties of $\mathrm{P} 92$ steel for different stress regimes at $650^{\circ} \mathrm{C}$ (defined based on Eq. 4)

\begin{tabular}{cccccc} 
& \multicolumn{2}{c}{ Secondary Creep } & \multicolumn{3}{c}{ Primary Creep } \\
\hline Stress Regime & $A_{s}$ & $n_{s}$ & $A_{p}$ & $n_{p}$ & $m_{p}$ \\
\hline $40<\sigma<85 \mathrm{MPa}$ & $1.50 \times 10^{-12}$ & 3.33 & $8.20 \times 10^{-10}$ & 3.05 & 0.28 \\
$85<\sigma<140 \mathrm{MPa}$ & $2.73 \times 10^{-17}$ & 5.8 & $8.20 \times 10^{-15}$ & 5.60 & 0.26 \\
$140 \mathrm{MPa}<\sigma$ & $1.00 \times 10^{-52}$ & 22.37 & $1.49 \times 10^{-49}$ & 20.94 & 0.35 \\
\hline
\end{tabular}

\subsection{Elastic Follow-Up Concept}

As discussed in Introduction, the term elastic follow-up describes a situation that occurs when the internal stresses redistribute throughout a structure by some form of nonlinear behaviour, such as plasticity and/or creep deformation [5]. The simplest method to describe creep stress relaxation in the presence of elastic follow-up is 
illustrated in Fig. 8a and b, where an initial residual stress is introduced by misfit [5]. Fig. 8a shows a two bar structure (i.e. two springs in series). Initially (step 1), both bars are in a neutral position; with one end fixed and the other free to move. In step 2 the bars are stretched to accommodate a misfit displacement $\mathrm{x}$, which introduces a tensile stress into each bar. It is assumed that the second bar exhibits creep deformations, while the first bar remains elastic. As the second bar creeps, strain is accumulated arising from by the tensile load introduced by the elastic recovery of the first bar. Fig. 8b illustrates the stress strain curve for the second bar, where the slope of the curve during creep deformation is a measure of the degree of elastic follow-up. The interaction between the two bars depends on their relative stiffness and an elastic follow-up factor, Z, describes the extent to which additional creep strain is accumulated [42]:

$Z=\frac{\Delta \varepsilon_{1}+\Delta \varepsilon_{2}}{\Delta \varepsilon_{1}}=\frac{\Delta \varepsilon_{c}}{\Delta \varepsilon_{e}}$

where $\Delta \varepsilon_{c}$ and $\Delta \varepsilon_{e}$ are the changes in equivalent creep strain, and reduced elastic strain; $\Delta \varepsilon_{1}$ and $\Delta \varepsilon_{2}$ are defined in Fig. 8b. The elastic follow-up factor $(Z)$ is bounded between a value of 1 which characterises pure fixed displacement and infinity $(\infty)$ which represents constant load. In the presence of elastic follow-up, the creep strain relaxation (Eq. 8) can be rewritten in this form:

$\dot{\varepsilon}_{c}=-\frac{\mathrm{Z}}{E} \frac{d \sigma}{d t}$

To estimate the elastic follow-up in a structure, there are various models designed so then that complex structures can be described by a set of series and parallel springs. Several benchmark models, discussed in earlier studies [7, 10, 43-48], adopt series, parallel, and combination systems. In the present work, a combination of bars was employed experimentally (see Section 2.3), while, for simplicity, the simulation was subjected to a series bar model.

For series bars, as shown in Fig. 8a, the two bar structure was subjected to a fixed displacement. In this simple model, each bar is modelled as a spring with stiffness of $k$. The relative stiffness $(\boldsymbol{\alpha})$ of the structure is [33]:

$\alpha=\frac{K_{1}}{K_{2}}$

where $K_{1}$ and $K_{2}$ are the stiffness for bar 1 and bar 2 . If it is assumed that bar 2 is creeping and bar 1 deforms elastically. The stiffness of each bar can be computed by:

$K=\frac{A E}{L}$

where $A, E$ and $L$ are cross section of area, elastic modulus, and length of each bar. The elastic follow-up of the structure is given by [33]:

$Z=\frac{\alpha+1}{\alpha}$ 

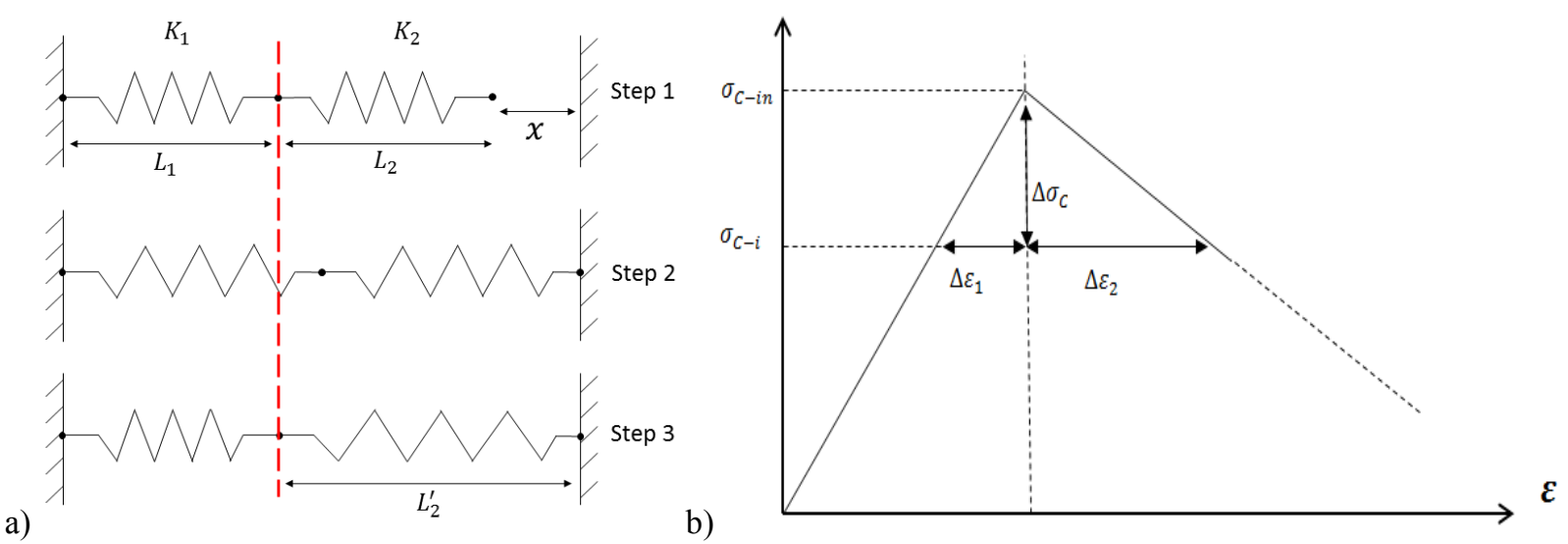

Fig. 8: a) Schematic definition of elastic follow-up using a two bar structure, b) Stress strain curve for the second bar in the presence of elastic follow-up only for elastic-creep deformation [5]

Based on this equation, the elastic follow-up of the structure depends only on the geometry (or stiffness) of the structure, rather the creep strain accumulation [5]. A similar approach to a series bar configuration can be applied for parallel bars, but the relative stiffness needs to be re-defined for parallel bars. Therefore, when there are $n$ parallel bars included (in the present study $n=2$ ) the relative stiffness assuming that bar 1 is creeping and bar 2 each deform elastically and identically [5] is given by:

$Z=\frac{n K_{2}}{K_{1}}$

For more complex structures, a combination of series and parallel bars can be considered as shown schematically in Fig. 9. In this equation, $K_{S}$ represents the stiffness of the bar experiencing creep deformation and is in series with a bar $\left(K_{i n}\right)$ which deforms only elastically. The middle section, consisting of two bars, is in parallel with the side bars $\left(K_{\text {par }}\right)$. This case is very similar to the parallel case, with the difference that the middle bar is replaced by a series bar. For such a combination, the elastic follow-up factor is:

$Z=Z_{e f f} Z_{\text {in }}=\left(\frac{\alpha_{e f f}+1}{\alpha_{e f f}}\right)\left(\frac{\alpha_{i n}+1}{\alpha_{i n}}\right)$

where,

$$
\left.\begin{array}{c}
\alpha_{i n}=\frac{K_{i n}}{K_{s}} \\
\alpha_{e f f}=\frac{2 K_{p a r}}{K_{e f f}} \\
\frac{1}{K_{e f f}}=\frac{1}{K_{s}}+\frac{1}{K_{i n}}
\end{array}\right\}
$$

where $K_{\text {eff }}$ is the effective stiffness of the middle bar. For such a combination of parallel and series bars, an initial residual stress in the specimen can be generated by misfit, external load, or a combination [5]. 

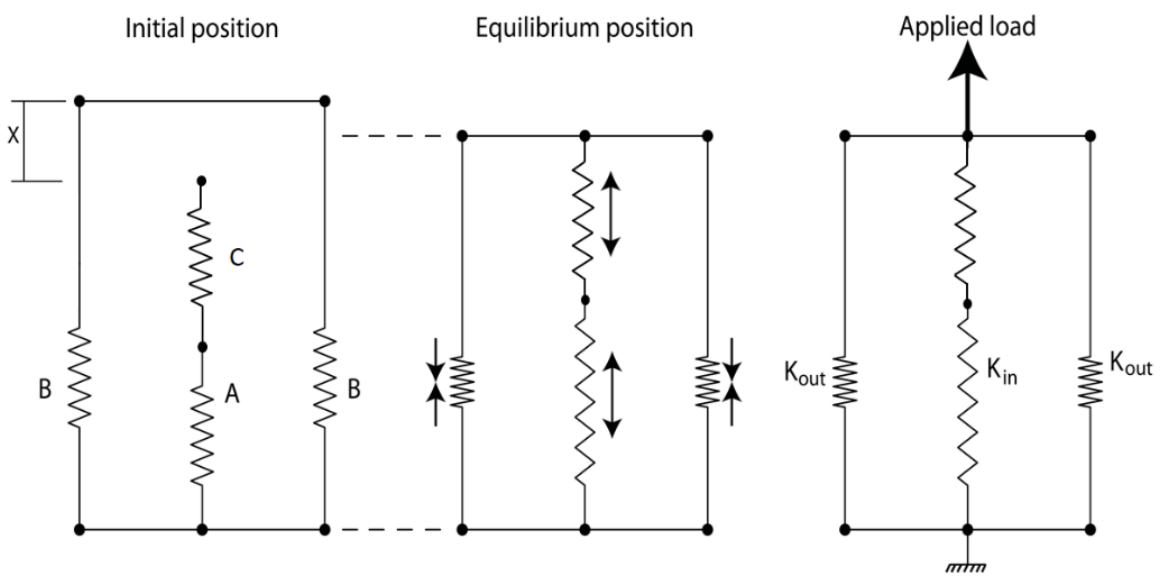

Fig. 9: A schematic of three bar structure containing an un-cracked component where located in the middle bar in series with spring A.

\subsection{Modelling Uniaxial Creep Elastic Follow-Up}

An axi-symmetric finite element model was used for a uniaxial specimen connected in series to a bar to predict the uniaxial creep stress relaxation under a variety of elastic follow-up and initial residual stress levels, as shown in Fig. 10. A two bar structure is a simple benchmark to investigate the relaxation of residual stress in a range of structural components [48, 49]. The model consists of two bars (Bar 1 and Bar 2, as shown schematically in Fig. 10), these bar 1 and bar 2 are either of a similar or different cross-sectional area and length connected in series. The dimensions of bar 1 and bar 2 have been selected in each model to accommodate a variety of elastic follow-up factors. The elastic follow-up factor for the structure was derived from the relative stiffness of the bars and a range of elastic follow-up factors was introduced by changing the stiffness of the series bar, see Section 4.3. In this model it was assumed that the series bar remains elastic, while the uniaxial bar undergoes elastic and creep deformation. The initial stress in this model was introduced by considering the misfit to the system. To impose the boundary condition, the bottom of the uniaxial bar was restricted to move in Y direction and free to move in X direction; displacement was applied to the top of the series bars. The commercial finite element package, ABAQUS, was employed for these simulations. The creep deformation as a function of stress, considering both primary and secondary creep (as described in Section 4.2), was implemented in ABAQUS using the CREEP subroutine. The CAX4 element type was selected for these simulations with number of 20 elements for each bar. The size, number and element type were picked after conducting mesh sensitivity study. It should be noted that for this simple bar geometry the influence of element size was found to be negligible. The assumption of time hardening and strain hardening was applied under conditions of variable stress [5]. 


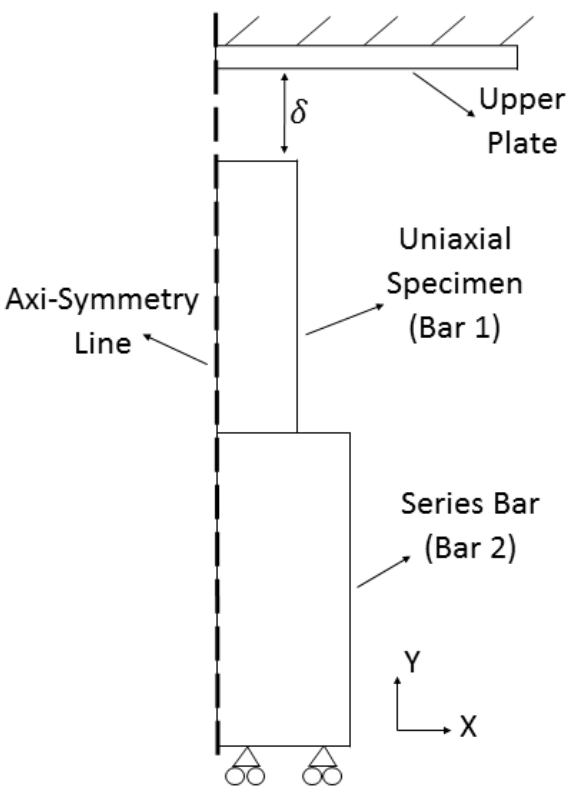

Fig. 10: Schematic illustration of an axi-symmetric model of a simple two bar structure, bar 1 and bar 2. Details of the FE analysis are described in the text.

\section{Discussion}

The experimental results embedded into the modelling indicate the importance of having stress dependent creep models to predict the relaxation of stresses particularly in the presence of high initial residual stresses. Fig. 11a and $b$ compare the FE predictions and experimental results for uniaxial creep stress relaxation with $\mathrm{Z}=1.7$ at $650^{\circ} \mathrm{C}$ with initial residual stress levels of $133 \mathrm{MPa}$ (Fig. 11a) and $99 \mathrm{MPa}$ (Fig. 11b). The FE predictions based on strain hardening provided a better prediction compared to a time hardening approach. This was obvious for $99 \mathrm{MPa}$ initial residual stress level (Fig. 11b). Fig. 11c and d illustrate a similar predictions with $\mathrm{Z}=1.17$ and initial residual stress levels of 123MPa (Fig. 11c) and 83MPa (Fig. 11d). However in the case of tests EFU-1 and EFU-3, the strain hardening approach provided better prediction compared to time hardening only for test EFU-2. For test EFU-4, which had the lowest initial residual stress level (83MPa) for the stress relaxation tests conducted, both methods do not compare favorably; but of the two the time hardening predictions was closer to experimental results. This is due to inaccurate estimated creep properties for stresses below 40MPa. In the present research, forward creep experiments were only carried out for stresses from 40MPa, and for lower stresses the creep properties were anticipated to be similar to regime $I$ in

Fig. $7(40 \mathrm{MPa}<\sigma<85 \mathrm{MPa})$ which represents a $n_{s}$ value of 3.3. However, it was proposed by other researchers $[11,14,50]$ that for relatively low stresses $(\approx 10 \mathrm{MPa}), n_{s}$ tends towards unity. Similarly, in some studies, conducted on a P91 steel $[11,14]$, the $n_{s}$ was evaluated to be around 1 at low stress levels using creep compression tests. This was argued to be due to a change in the creep deformation mechanism. Since the stress level in test EFU-4 decreased to below 10MPa (see Table 4 and Section 4.2), the proposed model in the present study would not be suitable to make these predictions. In general, the predictions for time hardening was lower bound and strain hardening were higher bound. 

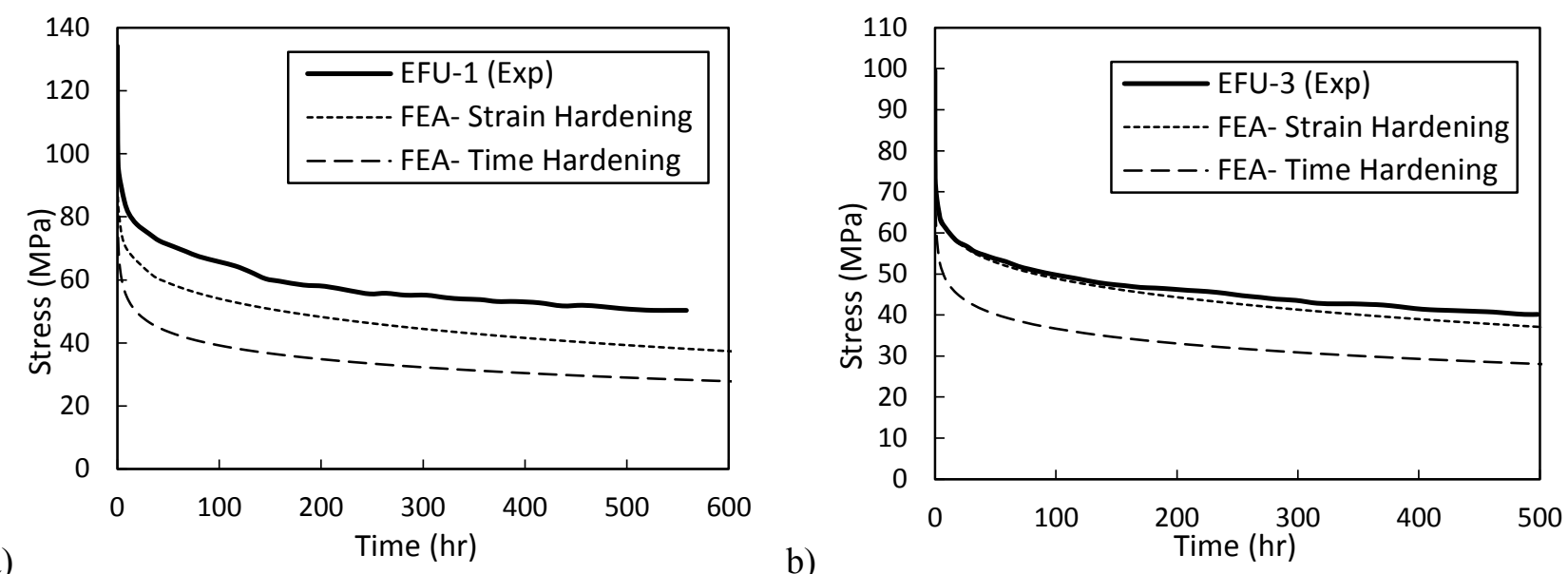

a)
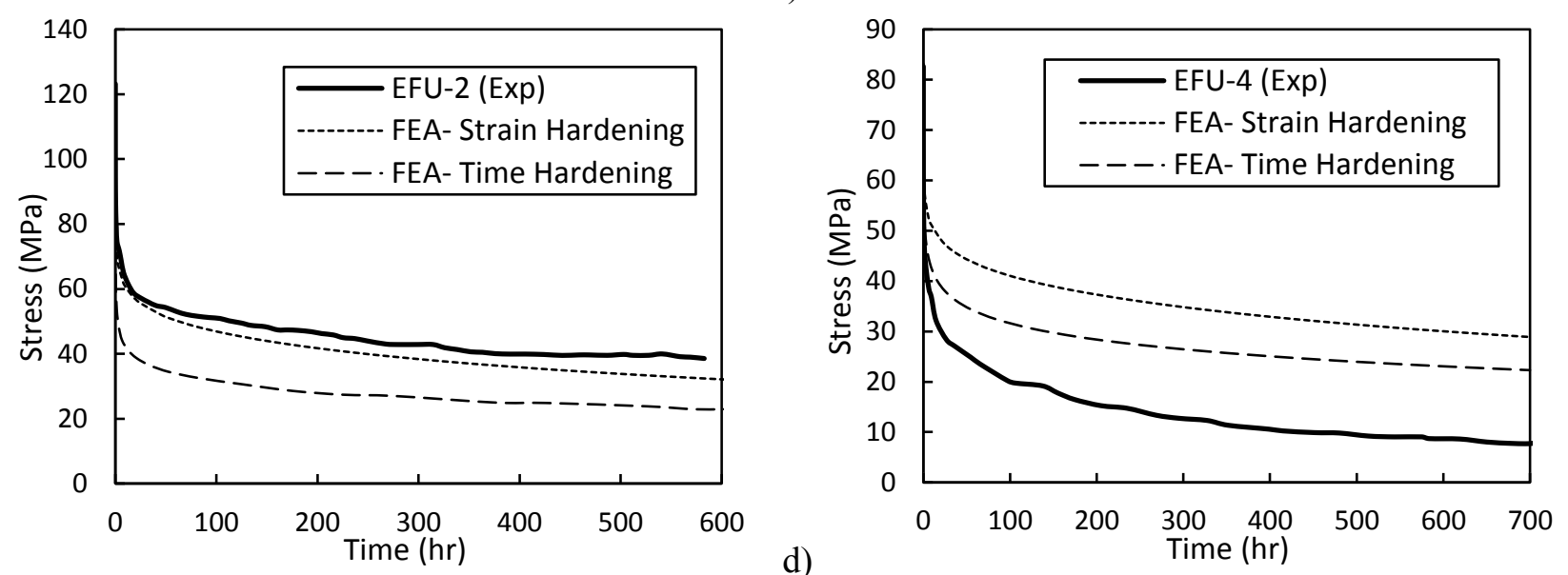

Fig. 11: Prediction of uniaxial creep stress relaxation for P92 steel at $650^{\circ} \mathrm{C}$, using strain hardening and time hardening approach compared with experimental results with elastic follow-up. a) Initial residual stress level of $133 \mathrm{MPa}(\mathrm{Z}=1.7)$, $\mathrm{b})$ initial residual stress level of 99MPa $(Z=1.7)$, c) Initial residual stress level of $123 \mathrm{MPa}(Z=1.17), d)$ initial residual stress

level of $83 \mathrm{MPa}(Z=1.17)$. The FE predictions were based on the primary-secondary stress dependant creep regimes.

In the case of uniaxial elastic follow-up for the P92 steel tests conducted at $650^{\circ} \mathrm{C}$, Fig. 12a compares the FE predictions, using the strain hardening and time hardening approaches. As shown in Fig. 5a, there was a higher level of creep strain accumulation in test EFU-3 compared to EFU-4, due to a higher initial residual stress and elastic follow-up. For both tests, the FE predictions based on time hardening approach were higher than the strain hardening approach. However, for test EFU-3, the FE predictions were higher than the experimental data and for test EFU-4, the experiment was higher than the FE predictions. This is similar to predictions for creep stress relaxation for test EFU-4 (Fig. 11d), where experimental results were lower than FE predictions, (opposite to other cases). As discussed earlier, insufficient experimental data at low stress levels results in inaccurate creep properties for creep strain predictions (see Sections 4.2 and Fig. 11d).

The experimental stress-strain curves compared with FE predictions, based on time hardening and strain hardening, are shown in Fig. 12b for the whole test period, including loading and relaxation. Hence the rate of stress relaxation followed the expected stress-strain trajectory associated with elastic follow-up for both experimental results and the FE predictions. The differences in the case of test EFU-1 due to the higher experimental elastic follow-up factor $\left(Z_{e}=1.83\right)$ compared to designed $(\mathrm{Z}=1.7)$. Both time hardening and strain hardening approaches provided identical curves regardless to the initial residual stress level and elastic followup factor. The response of the material to deformation at high temperature obeys the elastic follow-up factor using either a time or a strain hardening approach. Furthermore, time hardening predicts more stress relaxation 
(Fig. 11) and more creep strain accumulation (Fig. 12a) compared to strain hardening, so that time hardening productions pass through the path (slope of curve) faster than strain hardening.

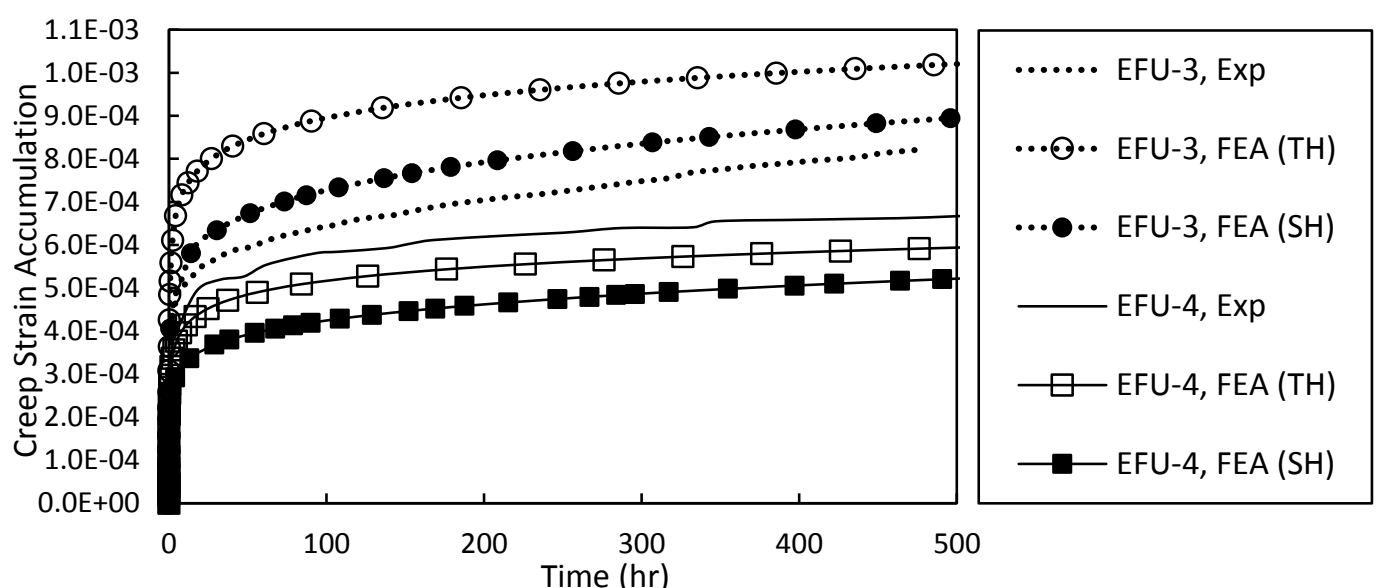

a)

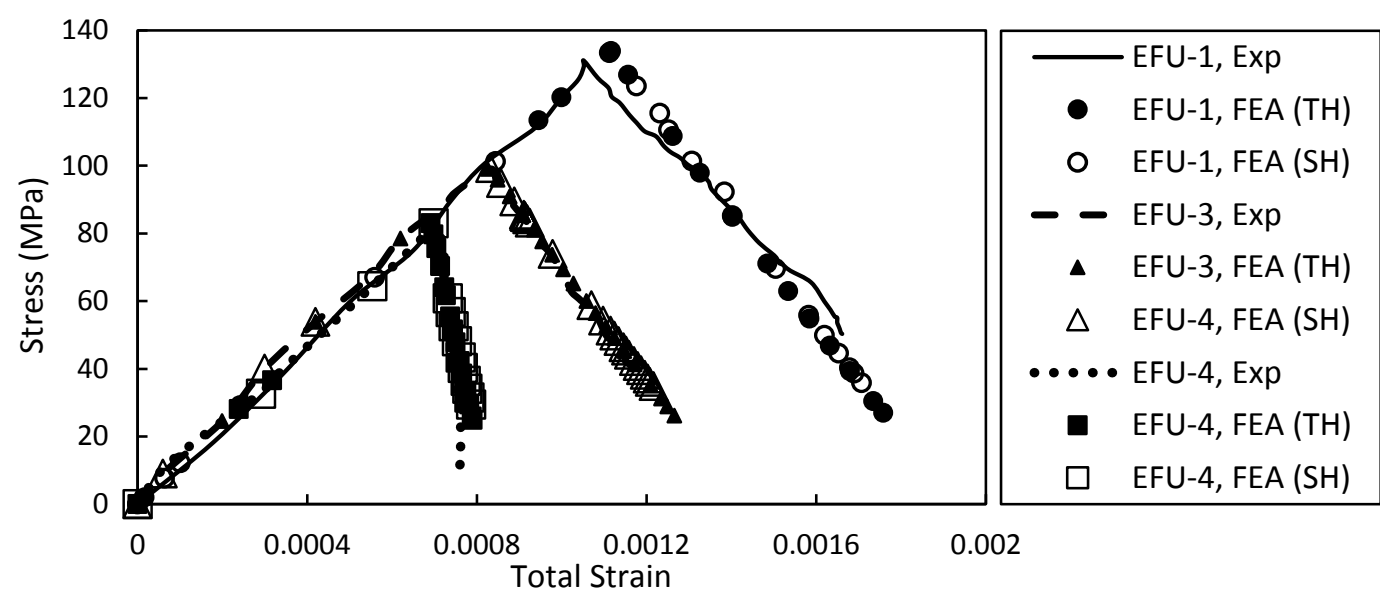

Fig. 12: FE predictions (using strain hardening and time hardening approaches) of uniaxial creep elastic follow-up compared to experimental results for $\mathrm{P} 92$ steel at $650^{\circ} \mathrm{C}$ : a) Creep strain accumulation curves. b) Stress-strain curve.

To predict creep strain accumulation (deformation) with more confidence, especially in presence of relaxation of stresses, there is a need to model both secondary creep and primary creep (Section 4.1). The traditional approach, used for example [51], takes into account secondary creep alone. Also discussed by Wang et al [24], there is a need to consider a combination of primary and secondary creep for each creep regime. This need is more pronounced for creep stress relaxation, especially in early stages where the primary creep is dominant. Fig. 13 compares the predictions made by strain and time hardening approaches for three different conditions: (i) primary-secondary stress dependent creep model (proposed in this study), (ii) secondary stress dependent creep properties (see Table 4), and (iii) a combination of primary and secondary creep only for mid-range stresses $(85<\sigma<140 \mathrm{MPa}$, stress independent).

The predictions based on the secondary stress dependent creep properties showed less stress relaxation especially in the early stages, whereas the new proposed model based on the combined primary and secondary stress dependent creep properties provided improved predictions. Although, the exact contribution of primary creep to stress relaxation and the time to achieve secondary creep remain unknown however the aspect is beyond the scope of the present paper. During secondary creep the slope of creep curve remains constant $\left(m_{s}=1\right)$, both time and strain hardening provided an identical predictions when using only secondary stress dependent creep properties (Fig. 13). The predictions based on the combination of primary and secondary creep from the middle regime (stress independent creep properties) provided a better prediction for early stages of relaxation compared to secondary stress dependent creep properties. 


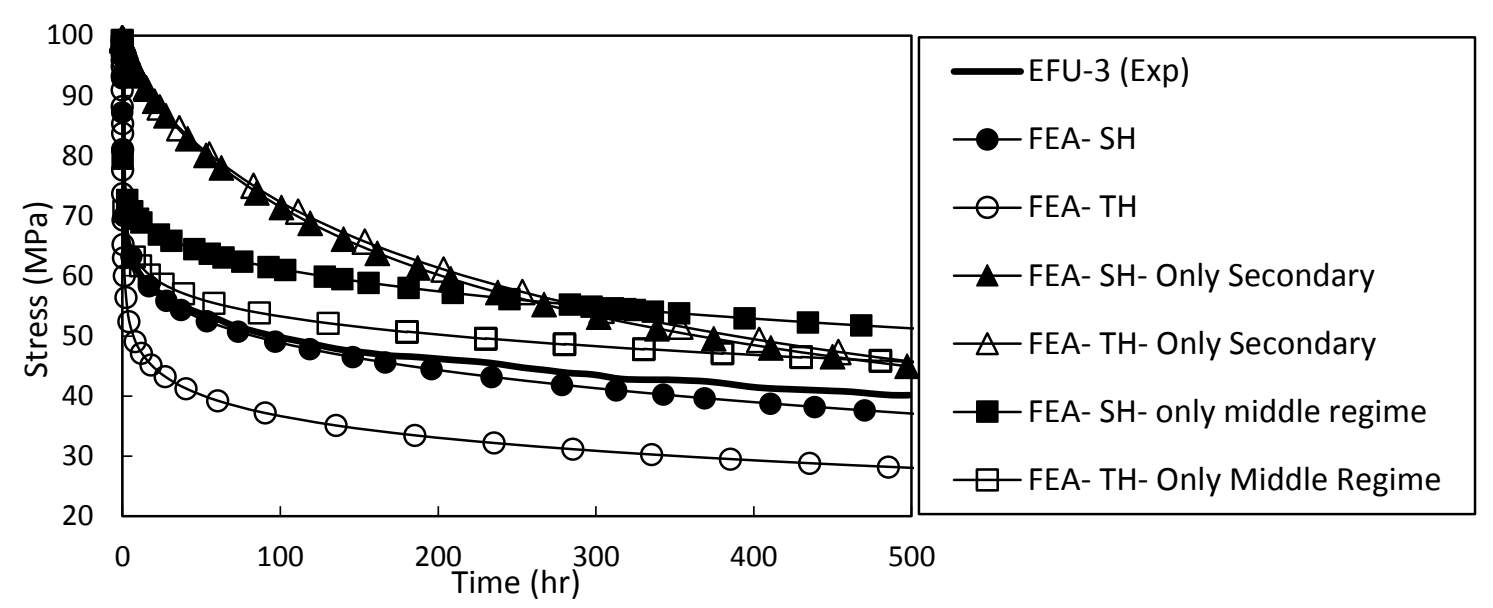

Fig. 13: Comparison of stress relaxation curves for 99MPa with elastic follow-up of 1.7 with the FE results (with and without considering primary creep and only middle creep regime properties for strain and time hardening)

Overall these combinations of experimental measurements and FE modelling reveal that there are number of parameters that have to be accommodated to models, e.g. stress dependent creep model, primary creep, and suitable creep properties for the stress region to understand stress relaxation. Different theories such as time or strain hardening, can affect the prediction of creep stress relaxation based on uniaxial creep data conducted at constant load. We have demonstrated that when the key parameters were evaluated the creep stress relaxation can be determined accurately, however additional experimental data under the required controlled conditions are needed to support the modelling predictions.

\section{Conclusions}

- It is necessary to have an accurate description of the creep properties of materials over a wide range of stresses, particularly when there is elastic follow-up. This study has presented results for creep deformation for a martensitic $\mathrm{P} 92$ steel at $650^{\circ} \mathrm{C}$ for a wide range of stresses. Uniaxial creep stress relaxation tests with elastic follow-up showed that the rate of stress relaxation increases by an increase in the elastic follow-up factor.

- A primary-secondary stress dependent creep model, consisting of three distinct stress regimes, was proposed. Primary-secondary stress dependent creep properties as well as secondary stress dependent creep properties and primary-secondary stress independent (data set from middle stress regime) creep properties have been adopted to predict creep stress relaxation for elastic follow-up conditions. Creep properties computed as primary-secondary stress dependent over a wide range of stresses were the most appropriate basic to predict relaxation of stresses and creep strain accumulation.

- Both time and strain hardening models used for predictions compared with the observed stress relaxation behaviour for the P92 steel. Strain hardening models provided improved predictions compared to time hardening.

- It was demonstrated that the majority of stress relaxation occurs in early stages where the primary creep is dominant.

- Regardless of using time or strain hardening approach, both provide an identical slope for stress-strain curve during creep, as this is a function of elastic follow-up. Nevertheless, the rate of time hardening is faster than strain hardening for a similar time. 


\section{ACKNOWLEDGEMENTS}

Saber Khayatzadeh would like to dedicate this paper to the memory of his supervisor, Professor David Smith, who was a simply wonderful colleague and friend. His sense of humour was matched by his brave, decisive and critical thinking which has had profound influence on my research. Despite our untimely goodbye, my colleagues and I will remember him forever. David Smith thanks the Royal Academy of Engineering, EDFEnergy, Rolls-Royce and the University of Bristol for supporting this work.

\section{REFERENCES}

[1] V. Sklenicka, K. Kucharova, M. Svoboda, L. Kloc, J. Bursik, and A. Kroupa, "Long-term creep behavior of 9-12\%Cr power plant steels," Mater. Charact., vol. 51, pp. 35-48, Aug. 2003.

[2] M. Ohgami, H. Naoi, S. Kinbara, H. Mimura, T. Ikemoto, and T. Fujita, "Developement of 9CrW Tube, Pipe and Froging for Ultra Supercritical Power Plant Boilers,” 1997.

[3] T. Sakthivel et al., "Creep rupture behavior of 9Cr-1.8W-0.5Mo-VNb (ASME grade 92) ferritic steel weld joint," Mater. Sci. Eng. A, vol. 591, pp. 111-120, Jan. 2014.

[4] L. Zhao, H. Jing, L. Xu, J. An, and G. Xiao, "Numerical investigation of factors affecting creep damage accumulation in ASME P92 steel welded joint," Mater. Des., vol. 34, pp. 566-575, Feb. 2012.

[5] S. Khayatzadeh, "Creep Deformation and Crack Initiation of Martensitic Steels under different Boundary Conditions," PhD Thesis, University of Bristol, 2015.

[6] S. Khayatzadeh, D. W. J. Tanner, C. E. Truman, and D. J. Smith, "Effect of Elastic Follow-up on Creep Crack Incubation," Procedia Mater. Sci., vol. 3, pp. 1485-1491, 2014.

[7] S. Khayatzadeh, D. W. J. Tanner, and D. J. Smith, "Creep crack incubation in P92 steel at $650{ }^{\circ} \mathrm{C}$ in the presence of structural elastic follow-up," in ASME 2015 Presure Vessels and Piping Conference, Boston, USA, 2015, pp. 1-10.

[8] R. Penny and D. Marriott, Design for creep. Chapman \& Hall, 1995.

[9] J. T. Boyle, “A re-assessment of elastic follow-up in high temperature piping,” Int. J. Press. Vessel. Pip., vol. 108-109, pp. 712, Aug. 2013.

[10] D. J. Smith, J. McFadden, S. Hadidimoud, a. J. Smith, a. J. Stormonth-Darling, and a. a. Aziz, "Elastic follow-up and relaxation of residual stresses," Proc. Inst. Mech. Eng. Part C J. Mech. Eng. Sci., vol. 224, no. 4, pp. 777-787, Apr. 2010.

[11] Y. Gorash, "Development of a creep-damage model for non-isothermal long-term strength analysis of high-temperature components operating in a wide stress range," PhD Thesis, Martin-Luther-Universitat Halle-Wittenberg University, 2008.

[12] A. A. Becker and T. H. Hyde, Fundamental Tests of Creep Behaviour. NAFEMS, 1993.

[13] M. Yurechko, C. Schroer, A. Skrypnik, O. Wedemeyer, and J. Konys, "Creep-to-rupture of the steel P92 at $650^{\circ} \mathrm{C}$ in oxygencontrolled stagnant lead in comparison to air," J. Nucl. Mater., vol. 432, no. 1-3, pp. 78-86, Jan. 2013.

[14] E. Hosseini, "prediction of long term creep rupture properties of welded joints using the results of short duration creep crack incubation tests," PhD Thesis, ETH Zurich University, 2013.

[15] M. Saber, "Experimental and Finite Element Studies of Creep and Creep Crack Growth in P91 and P92 Weldments," PhD Thesis, Nottingham University, 2011.

[16] W. Bendick, L. Cipolla, J. Gabrel, and J. Hald, "New ECCC assessment of creep rupture strength for steel grade X10CrMoVNb9-1 (Grade 91)," Int. J. Press. Vessel. Pip., vol. 87, no. 6, pp. 304-309, Jun. 2010.

[17] S. Hossain, "Residual stresses under conditions of high triaxiality," PhD Thesis, University of Bristol, 2005.

[18] W. Xue, Q. G. Pan, Y. Y. Ren, W. Shang, H. Q. Zeng, and H. Liu, "Microstructure and type IV cracking behavior of HAZ in P92 steel weldment," Mater. Sci. Eng. A, vol. 552, pp. 493-501, Aug. 2012.

[19] L. Zhao, H. Jing, L. Xu, Y. Han, and J. Xiu, "Experimental study on creep damage evolution process of Type IV cracking in 9Cr-0.5Mo-1.8W-VNb steel welded joint," Eng. Fail. Anal., vol. 19, pp. 22-31, Jan. 2012.

[20] L. Zhao, H. Jing, Y. Han, J. Xiu, and L. Xu, "Prediction of creep crack growth behavior in ASME P92 steel welded joint," Comput. Mater. Sci., vol. 61, pp. 185-193, Aug. 2012.

[21] J. S. Lee, H. G. Armaki, K. Maruyama, T. Muraki, and H. Asahi, "Causes of breakdown of creep strength in 9Cr-1.8W-0.5MoVNb steel,” Mater. Sci. Eng. A, vol. 428, no. 1-2, pp. 270-275, Jul. 2006.

[22] P. Ennis and A. Czyrska-Filemonowicz, "Recent advances in creep-resistant steels for power plant applications," Sadhana, vol. 28, no. 3-4, pp. 709-730, 2003. 
[23] E. I. Samuel, B. K. Choudhary, D. P. R. Palaparti, and M. D. Mathew, “Creep Deformation and Rupture Behaviour of P92 Steel at 923K," Procedia Eng., vol. 55, pp. 64-69, Jan. 2013.

[24] Y. Q. Wang, M. W. Spindler, C. E. Truman, and D. J. Smith, "critical analysis of the prediction of stress relaxation from forward creep of type 316H austenitic stainless steel," Mater. Des., vol. 95, pp. 656-668, 2016.

[25] B. Chen, D. J. Smith, P. E. . Flewitt, and M. W. Spindler, "Constitutive equations that describe creep stress relaxation for $316 \mathrm{H}$ stainless steel at 550 ${ }^{\circ}$," Mater. High Temp., vol. 28, no. 3, pp. 155-164, 2011.

[26] A. J. Moffat, J. P. Douglas, M. White, and S. Jacques, "Development of the RCC-MR creep deformation model for the prediction of creep and stress relaxation in Type 321 stainless steel," in ASME 2014 Pressure Vessels \& Piping Conference PVP2014, 2014.

[27] R. J. DeMelfi, “Application of a unified deformation rate law to stress relaxation of AISI-type 316 stainless steel," in Argonne National Laboratory, IL (USA), 1983.

[28] J. Douglas, M. Spindler, and R. Dennis, "Development of an Advanced Creep Model for Type 316 Stainless Steel," in Volume 9: Eighth International Conference on Creep and Fatigue at Elevated Temperatures, 2007, pp. 399-418.

[29] A. Fookes, S. Li, D. J. Smith, and M. Spindler, "Stress relaxation during dwells for creep and fatigue cycling of Type $316 \mathrm{H}$ stainless steel at 550ไtextsuperscript \{0\} C," in 2nd International ECCC Conference, Creep and Fracture in High Temperature Components-Design and Life Assesment, 2009.

[30] Y. Wang, "Design, Development and Experiments to Investigate the Effect of Elastic Follow-up on Creep Stress Relaxation in Austenitic Steels," PhD Thesis, University of Bristol, 2015.

[31] A. Skouras, "Generation and relaxation of residual stresses in dissimilar metal welds," PhD Thesis, University of Bristol, 2013.

[32] ASTM, "E8," Standard Test Methods for Tension Testing of Metallic Materials," Annu. B. ASTM Stand., 2004.

[33] A. Shirahatti, "A novel test rig to study the effects of elastic follow-up, long range residual stress and applied load on creep crack initiation," PhD Thesis, University of Bristol, 2014.

[34] G. Webster and R. Ainsworth, High temperature component life assessment. Chapman \& Hall, 1994

[35] C. Panait et al., "Long term aging effect on the creep strength of the T92 steel," in 9th Liege conference: Materials for Advanced Power Engineering, 2010.

[36] A. Mehmanparast, C. M. Davies, G. A. Webster, and K. M. Nikbin, "Creep crack growth rate predictions in 316H steel using stress dependent creep ductility," Mater. High Temp., vol. 31, no. 1, pp. 84-94, 2014.

[37] A. Mehmanparast, "Prediction of creep crack growth behaviour in $316 \mathrm{H}$ stainless steel for a range of specimen geometries," Int. J. Press. Vessel. Pip., vol. 120, pp. 55-65, 2014.

[38] J. W. Zhang, G. Z. Wang, F. Z. Xuan, and S. T. Tu, "The influence of stress-regime dependent creep model and ductility in the prediction of creep crack growth rate in Cr-Mo-V steel,” Mater. Des., vol. 65, pp. 644-651, 2015.

[39] J. W. Zhang, G. Z. Wang, F. Z. Xuan, and S. T. Tu, "Prediction of creep crack growth behavior in Cr-Mo-V steel specimens with different constraints for a wide range of C*," Eng. Fract. Mech., vol. 132, pp. 70-84, 2014.

[40] J. W. Zhang, G. Z. Wang, F. Z. Xuan, and S. T. Tu, "Effect of stress dependent creep ductility on creep crack growth behaviuor of steels for wide range of C*," Mater. High Temp., vol. 32, no. 4, pp. 369-376, 2015.

[41] X. Wang, Z. Shi, Q. Pan, and H. Wu, "High-temperature creep properties of fine grained heat-affected zone in P92 weldment," Trans Nonferrous Met. Soc. China, no. 20080430997, pp. 21-24, 2009.

[42] R5, “Assessment procedure for the high temperature response of structures,", British Energy, Gloucter, UK, 2003.

[43] S. Hadidi-Moud and D. J. Smith, "Use of elastic follow-up in integrity assessment of structures," ASME 2008 Press. Vessel. Pip. Conf. PVP2008, pp. 1-9, 2008.

[44] G. Horne and D. J. Smith, "Determination of the interaction between primary and secondary stresses using an idealised model," in ASME 2012 Pressure vessels \& pipping, Toronto, Ontario, Canada, July 15-19, 2012.

[45] S. Hadidi-Moud and D. J. Smith, "Estimation of Elastic Follow-Up in Structures," Key Eng. Mater., vol. 462-463, pp. 361365, Jan. 2011

[46] C. Aird, S. Hadidi-Moud, C. E. Truman, and D. J. Smith, "Impact of residual stress and elastic follow-up on fracture,” J. ASTM Int., vol. 5, no. 8, pp. 1-14, 2008.

[47] A. . Shirahatti, C. E. Truman, and D. J. Smith, "Experiments to Determine the Influence of Residual Stress and Elastic FollowUp on Creep Crack Initiation," in ASME 2013 Pressure Vessels \& Piping Conference PVP2013, 2013, pp. 1-10.

[48] Y. Wang, D. J. Smith, and C. E. Truman, "Inelastic Deformation and Elastic Follow-Up," in ASME 2013 Pressure Vessels \& Piping Conference PVP2013, Paris, France, July 14-18, 2013, pp. 1-10. 
[49] J. T. Boyle, "Stress relaxation and elastic follow-up using a stress range-dependent constitutive model," Proc. Inst. Mech. Eng. Part C J. Mech. Eng. Sci., vol. 226, no. 6, pp. 1472-1483, Oct. 2011.

[50] J. T. Boyle, "Some consequences of stress range dependent constitutive models in creep," Adv. Struct. Mater., vol. 19, pp. 7786,2013

[51] A. Mehmanparast, "The influence of inelastic damage on creep, fatigue and fracture toughness," PhD Thesis, Imperial College London, 2012. 